and of its principal restlts. In seconding a vote of thanks to Dr. Murray, Prof. Milne-Edwards availed himself of the opportunity of complimenting him, in terms of the highest eulogy, on the completion of the Challenger Reports, the cost of which has been so liberally met by the British Government, and the editorship of which has been in the hands of Dr. Murray since the death of the late Sir Wyville Thomson.

Prof. Weismann's lecture to the general meeting treated of a much more abstruse and complicated subject, viz. Germinal Selection. Under this name he introduced what he holds to be a supplementary hypothesis to that of Natural Selection, and by which he explains the fact that useful variations appear to be protected from their very first appearance, so that, when natural selection would require them, they are indeed always there. The simultaneous development of harmonious variations of different parts of the same organism was at the same time elucidated on similar principles.

It may be noticed in passing, that these theoretical views of Weismann's approach very closely to views expressed as the result of quite different series of palæontological observations by W. B. Scott and others. It is clear that an explanation of certain groups of facts is yet wanted. Weismann will have to show that his speculations do indeed bridge this gap.

In the three general meetings other questions of international significance were settled. In the first one, presided over by the Minister of the Interior, Mr. van Houten, the prize to which the name of the present Emperor of Russia is attached was awarded to Dr. R. T. Scharff, of Dublin. In the second one, of Wednesday, September I9, the conclusions of a report of M. Bouvier, on the question of bibliographical reform, were unanimously carried, and seven members of the Controlling Commission nominated, viz. Messrs. Spengel, Sidney Hickson, W. B. Scott, Blanchard, Hoek, Schimkevitch, and Lang.

Another commission for the definite codification of the rules of zoological nomenclature was appointed, and consists of Messrs. Blanchard, Victor Carus, Jentink, Sclater, and Wardell Stiles.

In the final mecting, Sir William Flower was nominated to the presidency of the next Zoological Congress, in 1808 . Upon the proposition of the President of the Congress, in the name of the Committee of Organisation, it was decided to meet in England, the exact place of meeting being left to the consideration of the vermanent Bureau.

During the Congress, as has already been announced in NAture, three of its most eminent members-Messrs. Weismann, Milne-Edwards, and Sir Wm. Flower-received the honorary degree of Doctor in Science (Section of Zoology and Botany) from the Senate of the Utrecht University, upon the proposal of the Faculty of Natural Philosophy.

On Saturday the meeting closed, and the members united in a farewell banquet in the concert hall, where the Minister of the Interior was again present.

On Sunday, the 22nd, the Amsterdam Zoological Society Natura Artis Magistra invited the members to a luncheon party, and to a visit to its well-known gardens and aquarium.

After this the members of the Congress definitely separated. There is not one of them who has not extended the circle of his personal acquaintance amongst his fellow-workers in the field of zoology. And this extension of the feelings of international scientific fraternity is one of the great advantages of these cosmopolitan gatherings.

\section{THE INTERNATIONAL CONGRESS OF PHYSIOLOGISTS AT BERN.}

I.

MONDAY, September 9.- Presidents, Profs. Chauveau and Bowditch. Dr. Boruttau (Göttingen) demonstrated on a platinum wire contained in a glass tube filled with $\cdot 6$ per cent. salt solution, electrical changes (negative variation), analogous to those occurring upon stimulation of a nerve trunk. The negative variation occurred not only upon electrical, but also upon chemical and mechanical stimulation of the wire. The apparatus used for the purpose were a Hermann's repeating rheotome and a Thomson's galvanometer.

Profs. Ewald and Goltz (Strassburg) showed a dog from which they had removed, at three successive stages, large portions of the spinal cord. In all $158 \mathrm{~mm}$. had been removed; this involved all the spinal cord below the middle dorsal region, inclusive of the cauda equina. The dog had already survived the last operation two years. The condition was as follows :(I) Entire muscular degeneration of hind limbs, and back muscles below mid-dorsal region; (2) evacuation of freces, and sphincter ani ext., normal; (3) large quantities of urine collected in bladder, but were eventually evacuated; (4) vascular tone normal. Animal gave birth to young ones since last operation, and suckled them normally.

Prof. Fano (Florence) showed a special apparatus by which he could measure exactly motor reaction time. Ife worked on the dog, and found that it was 32.6 sec. for anterior paw, 27.32 for posterior. After removal of parts of cortical layer of frontal and occipital lobes this reaction time was diminished; upon stimulation of same regions it was increased. From this the author concluded that the cortical cells, especially of the frontal region, exert a constant inhibitory action on the spinal cord.

Prof. Langley (Cambridge) gave a demonstration on (I) the general anatomical relations of the sympathetic system; (2) connection of nerve cells and nerve fibres; (3) reflexes from the sympathetic system.

Dr. Mann (Edinburgh) rearl a paper, accompanied by lanternslides, and gave a demonstration on the position of the psychomotor areas in the rabbit, hedgehog, dog, and cat. The result of the author's rescarches was to show that (I) the same general scheme of arrangement of the psycho-motor areas holds good throughout the animal kingdom, and (2) that there exist in the above animals centres of varying psycho-motor value (higher and lower centres in the physiological sense).

Prof. Gaule (Ziirich) discussed the growth of muscle, and came to the conclusion that it was periodic, and that there exist in muscular fibres changes corresponding to these periods. $\mathrm{He}$ further discussed and showed the effect of excision of the inferior cervical ganglion upon the biceps and psoas of the same side. Within twenty-four hours of this excision these muscles increase in weight, and have their resistance to mechanical strain greatly diminished (rupture easily).

Prof. Vitzou (Bucharest) produced blindness in a monkey by removal of the occipital region of the brain; two years after the operation the animal recovered, to a slight extent, its sight. Unon examining the brain at the seat of the lcsion, he found a tissue of new formation ; this tissue was very vascular, and its extirpation reproduced the blindness. Histological examination of this tissue showed the presence of nervous elements, which the author regarded as of true new formation.

Dr. Demoor (Brussels) stained the brains of animals to which he had given a strong dose of morphine or chloral hydrate by Golgi's method. Demoor found that the plotoplasm of the cell processes in these animals presented a characteristic mannilliform aspect, which was not to be observed in normal animals. The author showed his preparations

Monday Afternoon.--Presidents, Prof. Hensen and Mosso.Prof. Herzen (Lausanne) described the characters of a gastric juice obtained by the author and Dr. Fremont (Vichy) from the isolated stomach of a dog. The osophagus was sutured to the duodenum, and a fistula was made, from which the gastric juice was collected. The juice was without smell or colour, was highly acid, and cotid digest its own weight of coagulated albumin. The author further gave the result of his researches on the influence of the spleen on pancreatic digestion. He found a given quantity of blood from the splenic vein, added to a pancreatic infusion, greatly increased its digestive power, whereas the same quantity of ordinary arterial blood did not.

Prof. Schiff (Geneva) discussed the effects of an isolated lesion of one pyramid, and showed that it produced degeneration in the pyramid only, and not in the pyramidal tract.

Dr. Giirber (Würzburg) described the results of his researches on the crystallisation of serum albumin. He treated horse serum after Hofmeister's method (ammonium sulphate), and obtained four kinds of crystals. The author showed diagrams of these, and gave the results of their analysis.

Prof. Tigerstedt (Stockholm) described a new apparatus, on the principle of Pettenkofer and Voit, for respiration experiments on man. The author's apparatus is of such volume as to be able to contain several men at the same time.

Tuesday Morning.-Presidents, Prof. Rutherford and Hegir. -Dr. His, junr. (Leipsig) supported Engelmann's view that the propagation of the rhythmic cardiac wave takes place from fibre to fibre. He could not confirm Kent's results. He found in mammals, including man, a single muscular bundle which showed cross striation, going from the inter-auricular down into

No. [353, vol. 52] 
the inter-ventricular septum, in the neighbourhood of a cusp of the mitral valve. The author divided this bundle by a transverse incision of $2 \mathrm{~mm}$., and found that after this the auricle and ventricle beat each with its own rhythm. This bundle contained no nervous elements.

Dr. Kaiser(Heidelberg) showed that upon pinching off the lower two-thirds of the partially emptied frog's ventricle, this portion remained motionless; but on subsequently clamping the bulbus arteriosus, tension being produced in the ventricle, it recommenced to beat. Dr. Kaiser explains this result by supposing the existence in the frog's heart of a series of neurons which are discharged by an impulse which starts in the sinus, so that the mechanism is that of a reflex action; he believes the pinching destroyed the continuity of the nervous apparatus, while it left the muscle intact.

Prof. Kronecker (Bern) demonstrated in a most striking manner the effect of a sudden arrest of the coronary circulation, by injecting paraffin melting at $39^{\circ} \mathrm{C}$. into the descending coronary artery. The heart at once stops and enters into marked fibrillar contraction, from which, except occasionally in young animals, it never recovers. This effect is not produced by ligature of the same artery; this, in Prof. Kronecker's opinion, is due to collateral circulation being at once established. From this experiment Kronecker infers that the cardiac rhythm is due to the activity of some structures which are exceedingly sensitive to sudden cessation of their blood supply; this is not true of muscles or nerve trunks, but is of a nerve plexus or a ganglion cell.

Dr. Magnus (Heidelburg) showed a sphygmograph for use on a dissected out artery.

Prof. Hurthle (Breslau) showed a new method of registering the arterial blood-pressure in man. The arm is made bloodless by means of an Esmark's bandage, and introduced into a phlethysmograph connected with a tambour. Hurthle also showed a method for simultaneously recording the heart movements and rendering audible the heart sounds. The latter was effected by a resonating-box placed against the chest-wall; to the box a wooden tuning-fork was attached; the limbs of this vibrated in unison with the heart sounds, and varied the intensity of a current led through the primary coil of an induction apparatus, and through a microphone placed between the limbs of the fork a telephone was connected with the secondary coil

Dr. White (London) made experiments to show that perfect cardiac perfusion was not obtained with a Kronecker's canula as modified by Williams, the actual perfusion in a Williams' only extending to the top of the end-piece.

Dr. Zuntz (Berlin) described a new method for determining the velocity of the blood; it consisted in injecting into the carotid artery, during arrest of the heart produced by stimula tion of the vagus, sufficient blood to bring the blood pressure back to the normal. Knowing the amount of blood which has to be injected, and the time this takes, the velocity of the blood, as well as the amount propelled by the heart, can be deduced.

Tuesday Afternoon. - Presidents, Profs. Wedensky and Tigerstedt. -Dr. A. Dastre (Paris) showed that if fresh fibrin is placed in strong neutral saline solutions, one finds after a certain time two globulins in the solution. (I) Globulin coagulating at $54^{\circ}$ (2) Globulin having the properties of serum globulin; and further, that proteose and true peptone are also present. This action of saline solutions on fresh fibrin can be divided into different stages. If fresh fibrin be submitted in the same manner to the action of the digestive juices, the same results are produced; it is then quite justifiable to speak of a "saline digestion" of fibrin. Fibrin submitted to the action of oxygenated water, and to that of micro-organisms, gave the same results. When gelatin is similarly treated, gelatoses are produced, and the gelatin loses its power of coagulation.

Dr. A. Beck (Lemberg) discussed the velocity of blood in the portal vein. The author found that the normal velocity was from 2000 to $2800 \mathrm{cms}$. per second, and that $0.62-0.79 \mathrm{grm}$. of blood flowed through 1 grm. of liver tissue in twenty-four hours. The author used Cybulsky's method.

Prof. Berry Haycraft (Cardiff) read a paper on the change of shape of the heart during contraction. The author found it difficult to kill animals with the heart in systole; this he finally did by injections of $\mathrm{HgCl}_{2}$. Killing animals with the heart in diastole presented no difficulty. The animals were frozen immediately after death, and sections of their hearts cut at different levels. The author's results confirmed those of Ludwig and Hesser.
Prof. F. Gotch (Oxford). The discharge of Malapterurus electricus. The electrical discharge of the organ evoked in the living fish by mechanical and electrical stimulation was investigated by the capillary electrometer, the frog nerve muscle galvanoscope, and the galvanometer. Each apparently single shock of the organ was found to be multiple in character, showing an initial primary, followed by several secondary elec. trical outbursts. The primary outburst had a latency of $4 / 1000^{\prime \prime}$ and a duration of $2 / 1000^{\prime \prime}$. The E.M.F. $=\mathrm{I} 20$ to 200 volts. The secondary effects which follow the primary are plainly perceptible in the isolated organ after killing the fish; hence the multiple character of the single secousse is due to the organ itself. Each of the secondary effects occurs at an interval of from $4 / 1000^{\prime \prime}-6 / 1000^{\prime \prime}$ after its predecessor. The primary as. well as the secondary effects are monophasic in character; hence a very profound physiological effect is produced.

F. W. Tunniciliffe.

\section{FORTHCOMING BOOKS OF SCIENCE.}

MESSRS. C. GRIFFIN \& CO., Ltd., will shortly issue :An exhaustive treatise on "Petroleum : the Geographical Distribution, Geological Occurrence, Chemistry, Refining, and Testing, \&c.," by Boverton Redwood and Geo. T. Holloway, in two volumes: "The Chemistry of Gas Manufacture: Handbook on the Production, Purification, and Testing of Illuminating Gas, and the Assay of the Bye-Products of Gas Manufacture," by W. J. Atkinson Butterfield ; "Chemistry for Engineers and Manufacturers," by Bloxam Blount and A. G. Bloxam, in two volumes : vol. i. "The Chemistry of Engineering, Building, and Metallurgy"; vol. ii. "The Chemistry of Manufacturing Processes"; "Electrical Measurements and Instruments : a Practical Handbook of Testing for the Electrical Engineer," by Charles H. Yeaman; "Textile Printing: a Practical Manual of the Processes used in the Printing of Cotton, Woollen, and Silk Fabrics," by C. S. Seymour Rothwell, with illustrative specimens (companion volume to the "Manual of Dyeing," by Messrs. Knecht and Rawson); "Bleaching and Calico-Printing : a Short Manual for Practical Men," by Geo. Duerr, with specimens designed specially to show various stages of the processes described ; a third edition, revised and enlarged, of the "Outlines of Practical Physiology," by Dr. William Stirling ; a fourth edition of "Foods: their Composition anc Analysis," and a third edition of "Poisons : their Effects and Detection," both enlarged and revised, by A. Wynter Blyth ; an eleventh edition, revised, of Munro and Jamieson's "Electrical Pocket-book" ; a third edition, also revised, of Seaton and Rownthwaite's "Marine Engineering Pocket-book"; a new issue, revised, of "Griffin's Electrical Engineer's Price-book," brought up to date and edited by H. J. Dowsing; a second edition, revised, of "The Design of Structures" by S. Anglin; and the thirteenth annual issue of "The Year-book of Scientific and Learned Societies of Great Britain and Ireland," comprising Lists of the Papers read before Societies engaged in Fourteen Departments of Research during 1895 .

In the Cambridge University Press's announcements we notice a series of volumes rlealing with geographical and cognate subjects, which will be under the general editor. ship of Dr. F. IH. H. Guillemard. The first volume will be by Prof. A. H. Keane, and will treat of Ethnology. This will be followed by "The Geographical Distribution of Mammals," by R. Lydekker. Mr. H. F. Tozer is to write on the "History of Ancient Geography"; and other volumes will deal with the "Renaissance Period of Geographical Discovery," by C. E. Ravenstein, and "Oceanography," by J. Y. Buchanan.; "The Scientific Papers of John Couch Adams," vol. i., edited by Prof. William Grylls Adams, with a memoir by Dr. J. W. L. Glaisher; "The Collected Mathematical Papers of the late Arthur Cayley," vol. ix. ; "A Treatise on Spherical Astronomy," by Sir Robert S. Ball ; "Catalogue of Scientific Papers compiled by the Royal Society of London," I $874-1883$, vol. xi. ; a second edition of Heath's "Treatise on Geometrical Optics; "A Treatise on Abel's Theorem," by H. F. Baker ; "A Treatise on the Lunar Theory," by E. W. Brown; "An Elementary Treatise on Electricity and Magnetism," by Prof. J. J. Thomson; "A Treatise on Geometrical Optics," by R. A. Herman. In the Pitt Press Mathematical Series: "Euclid," books xi. and 